\title{
Brain Monoaminergic Activity in Rainbow Trout Selected for High and Low Stress Responsiveness
}

Øyvind Øverli ${ }^{1 *}$, Tom G. Pottinger ${ }^{2}$, Toby R. Carrick ${ }^{2}$, Elisabeth Øverli ${ }^{3}$ and Svante Winberg ${ }^{4}$

${ }^{1}$ Evolutionary Biology Centre, Department of Animal Development and Genetics, Uppsala University, Norbyvägen 18A, S-752 36 Uppsala, Sweden

${ }^{2}$ NERC Centre For Ecology \& Hydrology, Windermere Laboratory, The Ferry House, Far Sawrey, Ambleside, Cumbria LA22 0LP, united Kingdom

${ }^{3}$ Uppsala University Hospital, SE-751 85 Uppsala, Sweden

${ }^{4}$ Evolutionary Biology Centre, Department of Comparative Physiology, Uppsala University, Norbyvägen 18A, S-752 36 Uppsala, Sweden

\footnotetext{
* Corresponding author

E-mail: oyvind.overli@devbiol.uu.se

Telephone: ++ 46184712649
}

Fax: ++ 46184712683 
Key words: Cortisol, Dopamine, Monoamines, Norepinephrine, Oncorhynchus mykiss, Serotonin, Stress responsiveness

\begin{abstract}
This paper investigates whether two lines of rainbow trout displaying genetically determined variation in stress responsiveness and behavior also show differences in brain monoaminergic activity. In several brain regions, strains of rainbow trout selected for consistently high or low post-stress cortisol levels displayed differences in tissue concentrations of monoamines and/or monoamine metabolites, or in metabolite/monoamine ratios. High-responsive trout reacted to stress by an increase in the concentrations of both serotonin (brain stem), dopamine (brain stem), and norepinephrine (optic tectum, telencephalon), whereas low-responsive fish did not. Brain stem and optic tectum concentrations of monoamine metabolites were also elevated after stress in high responders, but not in low-responsive fish. The simultaneous increase in the concentration of monoamines and their metabolites suggests that both synthesis and metabolism of these transmitters were elevated after stress in high-responsive trout. A divergent pattern was seen in the hypothalamus, where low-responsive fish displayed elevated levels of 5-hydroxyindoleacetic acid (a serotonin metabolite) and 3-methoxy-4hydroxyphenylglycol (a norepinephrine metabolite). In the telencephalon, both populations had elevated concentrations of these metabolites after stress. These results clearly suggest that selection for stress responsiveness in rainbow trout is also associated with changes in the function of brain monoaminergic systems. The possible functional significance of these observations is discussed with respect to the physiological and
\end{abstract}


behavioral profile of these strains of fish. Literature is reviewed showing that several factors affecting brain monoaminergic activity might be altered by selection for stress responsiveness, or alternatively be under direct influence of circulating glucocorticoids.

\section{Introduction}

Stress responsiveness, in terms of blood cortisol levels following exposure to a standardized stressor, is a consistent individual characteristic in rainbow trout, with a moderate to high degree of heritability [Fevolden et al., 1999; Pottinger and Carrick, 1999]. Recent studies have shown that strains of rainbow trout selected for high (HR) or low (LR) cortisol responsiveness also display differences in behavior [Pottinger and Carrick, 2001a; Øverli et al., 2001]. Consistent differences in stress responsiveness and behavior may indicate that HR and LR rainbow trout represent selection for differential stress coping strategies, or coping styles, as defined by Koolhaas et al. [1999].

Specifically, females from the LR population displayed a lower level of locomotor activity than HR fish, both when reared alone and in response to a conspecific territorial intruder [Øverli et al., 2001]. It would also appear that LR fish adapt more easily to new rearing conditions, since only fish from this population regained feed intake within one week after transfer from holding tanks to rearing in social isolation [Øverli et al., 2001]. In another experiment, involving juveniles from the third generation of selection for high or low post-stress cortisol values, it was found that LR fish became socially dominant 
over size-matched HR fish in staged fights for social dominance between pairs [Pottinger and Carrick, 2001a].

Little is known about the potential causative mechanisms underlying concomitant differences in stress responsiveness and behavior in fish. The behavioral and physiological characteristics of HR and LR rainbow trout may be functionally linked through a number of factors which influence both endocrine and behavioral responses, as well as through direct behavioral effects of cortisol.

The brain monoamine neurotransmitters dopamine (DA), norepinephrine (NE), and serotonin (5-hydroxytryptamine, 5-HT) are believed to be involved in the control and integration of behavioral and physiological stress responses in both teleost fish and mammals [Blanchard et al., 1993; Stanford, 1993; Winberg and Nilsson, 1993; Øverli et al., 1997, 1999; Höglund et al., 2000] and the behavioral and neuroendocrine effects of these signal substances appear to be similar among different vertebrate groups. Differences in brain monoaminergic functions also have been observed in animals displaying genetically determined variation in stress responsiveness and behavior [e.g. Bertolucci-D’Angio et al., 1990; Popova et al., 1991a, b; Nikulina et al., 1992; Rots et al., 1996a, b; De Kloet et al., 1996; Sallinen et al., 1998; Lepage et al., 2000]. It therefore could be hypothesized that selection for stress responsiveness in rainbow trout is associated with changes in brain monoaminergic activity. We report here the effect of a standardized stressor on tissue concentrations of DA, NE, and 5-HT, and their metabolites (3,4-dihydroxyphenylacetic acid [DOPAC], 3-methoxy-4hydroxyphenylglycol [MHPG], and 5-hydroxyindoleacetic acid [5-HIAA], respectively) 
along with corresponding metabolite/monoamine ratios in different brain regions in adult females from established HR and LR strains of rainbow trout.

\section{Materials and methods}

All experimental work was carried out within the requirements of the Animals (Scientific Procedures) Act 1986, UK. Brain and blood plasma samples were obtained from the experimental fish utilized in the behavioral studies described by Øverli et al. [2001]. In short, two F1 lines of rainbow trout (Oncorhynchus mykiss) divergent for the cortisol response to a standardized stressor (confinement) were generated by individual selection for consistently high or low post-stress cortisol values within the F0 generation [Pottinger and Carrick, 1999]. HR and LR F1 families were maintained at the Windermere Laboratory in 15001 outdoor tanks, supplied with lake water $\left(251 \mathrm{~min}^{-1}\right.$; stocking density

approx. $20 \mathrm{~g}^{1-1}$ ) at ambient temperature and fed three times weekly with commercial feed (Trouw Standard Expanded 40) at the manufacturers recommended rate.

During April 2000, adult female HR $(\mathrm{n}=18)$ and LR $(\mathrm{n}=18)$ rainbow trout weighing $987.5 \pm 39.5 \mathrm{~g}($ mean $\pm \mathrm{SE})$ were transferred from communal holding tanks to rearing in isolation in outdoor observation tanks. The polypropylene observation tanks $(250$, flow

rate $151 \mathrm{~min}^{-1}$ ) were covered with medium plastic mesh in order to prevent escape of the fish, while allowing for behavioral observations from above [Øverli et al., 2001]. The water temperature increased gradually from $6.2^{\circ} \mathrm{C}$ at the start of the experiment to $8.5^{\circ} \mathrm{C}$ at the end of the experiment. From day 1 after transfer to rearing in isolation, fish were 
fed daily by hand ( $1.5 \%$ of body weight). Only LR fish ( 7 out of 18 individuals) fed during the experiment.

On day $8,50 \%$ of the fish from each group were transferred to 501 confinement tanks which had previously been utilized to quantify the cortisol response in HR and LR rainbow trout [Pottinger and Carrick, 1999]. After 1h in the confinement tanks, fish were netted, anaesthetized in $0.5 \mathrm{ml} / 1$ 2-phenoxyethanol, and a blood sample was obtained from the caudal sinus into a heparinized syringe. Following blood sampling fish were killed by decapitation, and within 2 min after capture brains were removed and dissected into telencephalon (excluding the olfactory bulbs), hypothalamus (excluding the pituitary), optic tectum, and brain stem (excluding the cerebellum), following the protocol of Øverli et al. [1999]. Brain samples were immediately wrapped in aluminum foil and frozen in liquid nitrogen, before being transferred to storage at $-80^{\circ} \mathrm{C}$. Blood samples were kept on ice for $<1 \mathrm{~h}$ before being centrifuged ( $3000 \mathrm{~g}$ at $4^{\circ} \mathrm{C}$ for $\left.10 \mathrm{~min}\right)$. Separated plasma was transferred to polypropylene tubes and stored frozen $\left(-20^{\circ} \mathrm{C}\right)$ until analyzed for plasma cortisol.

The remaining $50 \%$ of the fish from each group were sampled directly from the observation tanks, to serve as undisturbed controls, but otherwise sampled as described above. All sampling was carried out between 10.00 and 14.00, on four separate days, with an equal number of stressed and control LR and HR fish sampled each day. Thus, for the analysis of plasma cortisol and brain neurochemistry four experimental groups were established: HR controls, LR controls, HR stressed, and LR stressed ( $n=9$ in all groups). 
Plasma cortisol levels were determined using a previously validated cortisol radioimmunoassay [Pickering et al., 1987], and concentrations of monoamines and monoamine metabolites in brain samples were analyzed by HPLC with electrochemical detection, as described by Øverli et al. [1999].

It should be noted that both controls and stressed fish had previously been tested for behavioral activity in the presence of a conspecific intruder the day before sampling (data presented in Øverli et al. [2001]). It is however assumed that the fish had recovered from any stress effects of the intruder test. In a previous experiment it was shown that immediately (within 5min) after fights for social dominance both dominant and subordinate rainbow trout had elevated cortisol levels, but this response was abolished and cortisol levels had decreased to control levels in fight winners within $3 \mathrm{~h}$ after the termination of fights [Øverli et al., 1999]. When pairs of rainbow trout were split and fish left in isolation after fights for dominance, neither dominant or subordinate fish showed any elevation of plasma cortisol or activation of brain monoaminergic systems when sampled 3h or $24 \mathrm{~h}$ after fights (Ø. Øverli and S. Winberg, unpublished data).

Using the Levene test (homogeneity of variances) and normal probability plots, it was found that concentrations of cortisol, monoamines, and monoamine metabolites in control and stressed HR and LR fish fulfilled the criteria for parametric statistics. Data were analyzed by ANOVA, followed by the Tukey HSD post-hoc test when significant group differences were indicated by the ANOVA. As a further index of brain monoaminergic 
activity, monoamine / metabolite ratios were calculated and compared between groups as described above.

\section{Results}

\section{Plasma cortisol}

Plasma cortisol concentrations in LR and HR rainbow trout sampled directly from rearing in isolation (controls) and following $1 \mathrm{~h}$ confinement stress are shown in table 1. Compared to controls, both LR and HR rainbow trout displayed increased cortisol concentrations after $1 \mathrm{~h}$ of confinement (ANOVA statistics: $F(3,32)=6.23, \mathrm{p}=0.002$; post hoc: $p=0.02$ and $p=0.009$, for LR and HR, respectively). Furthermore, HR fish had higher cortisol than LR fish after stress (post hoc: $p=0.04$ ), but this difference was not significant in fish sampled directly from rearing in isolation (post hoc: $p=0.16$ ).

\section{Brain Serotonergic Activity}

Concentrations of monoamines and monoamine metabolites, and corresponding monoamine/metabolite ratios, are shown in figures $1-4$. The clearest effects of $1 \mathrm{~h}$ confinement stress on serotonergic activity were seen in the brain stem and telencephalon. (Fig. 1A-C, 2A-C). HR fish but not LR fish $(\mathrm{p}=0.15)$, displayed significantly increased 5HIAA concentrations in the brain stem after confinement stress, as compared to controls from the same population $(\mathrm{F}(3,32)=9.37, \mathrm{p}<0.001$; post hoc: $\mathrm{p}<0.001$ and $\mathrm{p}=0.15$, for HR and LR, respectively; fig. 1A). Possibly, the stress induced increase in 5-HIAA concentrations did not reach statistical significance in LR fish, since there was a trend 
towards increased 5-HIAA in this group even in the control condition (fig. 1A). On the other hand, 5-HIAA/5-HT ratios were significantly higher in LR than HR fish both in the control condition $(\mathrm{F}(3,32)=20.97, \mathrm{p}<0.001$; post hoc: $\mathrm{p}=0.02$; fig. $1 \mathrm{C})$ and after confinement stress (post hoc: $\mathrm{p}=0.001$; fig. 1C), even though both groups displayed significant increases after stress as compared to controls (post hoc: $p=0.005$ and $p<$ 0.001, for HR and LR, respectively). Possibly contributing to the difference in 5-HIAA/5HT ratios after stress was the fact that stressed HR fish had higher concentrations of 5-HT in the brain stem than had stressed LR fish $(F(3,32)=2.90, p=0.049$; post hoc: $p=0.04$; fig. 1B).

Concentrations of 5-HT were not significantly different between groups in any other brain region than the brain stem (telencephalon: $\mathrm{F}(3,32)=0.39, \mathrm{p}=0.76$, fig. $2 \mathrm{~B}$; optic tectum: $F(3,32)=0.95, p=0.43$, fig. 3B; hypothalamus: $F(3,31)=0.12, p=0.94$, fig. 4B). Confinement stress however led to increased telencephalic 5-HIAA concentrations $(\mathrm{F}(3,27)=8.96, \mathrm{p}<0.001$; post hoc: $\mathrm{p}=0.003$ and $\mathrm{p}=0.04$, in HR and LR fish, respectively, fig. 2A) in both populations. Telencephalic serotonergic activity was not different between LR and HR rainbow trout after stress, but in the control condition LR fish again had significantly higher 5-HIAA/5-HT ratios than HR fish had (post hoc: $p$ $=0.04$, fig. $2 \mathrm{C}$ ). In the optic tectum parameters of 5-HT activity were not significantly different between comparable experimental groups (5-HIAA concentrations: $\mathrm{F}(3,32)=$ $3.94, p=0.017$, but post hoc tests indicated that this effect was due to a difference between LR controls and stressed HR fish only, fig. 3A; 5-HT concentrations: F(3,32) = $0.95, \mathrm{p}=0.43 ; 5$-HIAA/5-HT ratios: $\mathrm{F}(3,32)=3.55, \mathrm{p}=0.025$, but post hoc comparisons 
were non-significant; fig. 3B, C). In the hypothalamus LR rainbow trout had higher 5HIAA concentrations than HR fish both in the control condition $(F(3,31)=8.89, \mathrm{p}<$ 0.001; post hoc: $\mathrm{p}=0.03$ ) and after confinement stress (post hoc: $\mathrm{p}=0.03$, fig. $4 \mathrm{~A}$ ), whereas neither 5-HT concentrations $(\mathrm{F}(3,31)=0.12, \mathrm{p}=0.94)$, nor 5-HIAA/5-HT ratios $(\mathrm{F}(3,31)=0.83, \mathrm{p}=0.49)$ was a affected in this brain area (fig. $4 \mathrm{~B}, \mathrm{C})$.

\section{Brain Dopaminergic Activity}

Several differences in brain catecholaminergic activity between LR and HR rainbow trout were evident, but in this case significant differences between the two groups were only present following confinement stress. A major difference was that HR fish responded to stress by an increase in DOPAC concentrations in the brain stem $(\mathrm{F}(3,32)=11.21, \mathrm{p}<$ 0.001; post hoc difference to HR controls: $p=0.007$ and difference to stressed LR fish: $p$ $<0.001)$ and optic tectum $(\mathrm{F}(3,32)=8.90, \mathrm{p}<0.001$; post hoc difference to HR controls: $p=0.02$, difference to stressed LR fish: $p=0.001$ ), whereas LR fish did not (fig. 1D, 3D). In the optic tectum HR fish also displayed significantly higher DOPAC/DA ratios than LR fish after confinement stress $(F(3,32)=5.59, p=0.003$; post hoc $p=0.01$; fig. 3F). Furthermore, brain stem DA concentrations were significantly different between the two populations after stress, HR fish again displaying the highest concentrations $(F(3,32)=$ $2.92, p=0.048$; post hoc $p=0.04$; fig. 1E). Parameters of dopaminergic activity were not significantly different between groups in the telencephalon (DOPAC concentrations: $\mathrm{F}(3,327)=2.04, \mathrm{p}=0.13$; DA concentrations: $\mathrm{F}(3,27)=0.46, \mathrm{p}=0.52$; DOPAC/DA ratios: $\mathrm{F}(3,27)=1.69, \mathrm{p}=0.19$; fig. $2 \mathrm{D}-\mathrm{F})$ or hypothalamus (DOPAC concentrations: $\mathrm{F}(3,29)=0.70, \mathrm{p}=0.56$; DA concentrations: $\mathrm{F}(3,31)=1.12, \mathrm{p}=0.36$; DOPAC/DA 
ratios: $F(3,29)=0.85, p=0.48$; fig. $4 \mathrm{D}-\mathrm{F})$. In the latter brain parts, some samples could not be analyzed for catecholamine metabolites due to unknown interfering peaks in the chromatograms.

\section{Brain Noradrenergic Activity}

Similar to what was the case for DOPAC, only HR fish responded to stress by significant increases in the concentration of the NE metabolite MHPG in the brain stem $(\mathrm{F}(3,32)=$ 4.69, $\mathrm{p}=0.008$; post hoc $\mathrm{p}=0.03$; fig. $1 \mathrm{G})$ and optic tectum $(\mathrm{F}(3,32)=6.96, \mathrm{p}<0.001$; post hoc $p=0.004$; fig. $3 \mathrm{G}$ ) as compared to controls, but differences between the two populations were not significant in this case. On the other hand, again potentially as a result of differences in neurotransmitter concentrations, brain stem MHPG/NE ratios were significantly elevated after stress in LR fish as compared to controls $(F(3,32)=4.95$, $\mathrm{p}=0.006$, post hoc $\mathrm{p}=0.04)$, but not in HR fish (post hoc $\mathrm{p}=0.11$; fig. $1 \mathrm{I})$. A highly significant increase in optic tectum NE concentrations was also seen in HR fish following confinement stress $(F(3,32)=8.99, \mathrm{p}<0.001$; post hoc difference to controls $\mathrm{p}=0.004$ difference to LR fish $\mathrm{p}=0.002$; fig. $3 \mathrm{H})$.

In the telencephalon, both LR and HR fish responded to stress by highly significant increases in MHPG concentrations $(F(3,29)=20.21, p<0.001$; post hoc difference to controls $p<0.001$ for both strains; fig. $2 \mathrm{G}$ ). Due to the stress induced increase in NE concentrations present in $\mathrm{HR}$ fish $(\mathrm{F}(3,27)=4.16, \mathrm{p}=0.02$; post hoc difference to controls: $\mathrm{p}=0.04$; fig. $2 \mathrm{H}), \mathrm{MHPG} / \mathrm{NE}$ ratios were significantly affected by confinement stress only in LR fish $(F(3,27)=11.50, p<0.001$; post hoc difference to controls: $\mathrm{p}<$ 
0.001; fig. 2I) (Fig. 2C). A different pattern was seen in the hypothalamus, where only LR fish displayed a significant increase in MHPG concentrations after stress $(F(3,30)=$ $5.19, p=0.005 ;$ post hoc difference to controls $p=0.04$ ), and no effects were seen on NE concentrations $(\mathrm{F}(3,28)=0.34, \mathrm{p}=0.79)$ or MHPG/NE ratios $(\mathrm{F}(3,28)=2.24, \mathrm{p}=0.11$; fig. $4 \mathrm{H}, \mathrm{I})$.

\section{Discussion}

The cortisol data confirm that rainbow trout selected for high (HR) and low (LR) cortisol responsiveness to stress display differential hypothalamus-pituitary-interrenal (HPI) axis activity [Pottinger and Carrick, 1999]. Notably, behavioral observations carried out during rearing in isolation suggested an inhibition of both territorial behavior and appetite in the experimental fish [Øverli et al., 2001], further indicating that rearing conditions were not optimal in this experiment. Thus, it is possible that some observed differences between HR and LR fish sampled directly from rearing in isolation would not have been present during rearing in a completely stress free environment. A significant effect of confinement stress on plasma cortisol could however be seen in both populations, and fish not exposed to confinement stress are therefore referred to as controls throughout this paper. For comparison, it could be mentioned that plasma cortisol levels in group-reared fish from the same batches that were utilized in the current experiment were measured during January, 2000. At this time, when cortisol levels are normally elevated by sexual maturity, the mean cortisol level in females $(\mathrm{n}=12)$ was $59 \mathrm{ng} / \mathrm{ml}(\mathrm{SD}=22.9)$ with no difference between HR and LR fish. 
It is also possible that brain monoaminergic activity was affected by the inhibition of food intake, which was complete throughout the experiment in HR, but not in LR fish [Øverli et al., 2001]. Both 5-HT and the catecholamines are synthesized from essential amino acids (tryptophan and tyrosine, respectively), and, at least for 5-HT, precursor availability has been shown to be of great importance for synthesis rate, neurotransmission, and behavior [Boadle-Biber, 1993; SheaMoore et al., 1996; Aldegunde et al., 2000]. Winberg et al. [1992] however found that starvation for 4 weeks did not affect brain serotonergic activity in Arctic charr (Salvelinus alpinus), while chronic stress led to elevated 5HIAA/5-HT ratios. Looking more closely into the results of the current experiment, we found that out of the 7 LR fish that had been eating during the experiment, 5 were found among the fish subjected to the confinement test, and 2 in the control group (data not shown in the results section). Thus, out of 9 LR fish subjected to confinement, 5 could be classified as 'feeders', whereas 4 were 'non-feeders'. These numbers were arguably low, limiting the power of statistical tests for an effect of feeding status on monoaminergic activity. However, if anything, brain stem concentrations of DA (137.8 $\pm 8.3 \mathrm{ng} \mathrm{g}^{-1} \mathrm{vs}$ $\left.118.4 \pm 3.7 \mathrm{ng} \mathrm{g}^{-1}\right)$ and $5-\mathrm{HT}\left(559.8 \pm 44.8 \mathrm{ng} \mathrm{g}^{-1}\right.$ vs $\left.511.2 \pm 25.5 \mathrm{ng} \mathrm{g}^{-1}\right)$ would appear to be higher in non-feeding than feeding fish, an observation which does not support a theory of reduced neurotransmitter concentrations due to altered precursor availability in non-feeding fish.

When interpreting the various parameters of brain monoaminergic activity, special attention should be paid to the fact that altered monoamine/metabolite ratios may be caused by changes in the concentrations of monoamine neurotransmitters as well as 
metabolites, or by combinations of such changes. Thus, differential patterns of activation may be assumed depending on whether concentrations or ratios are studied. An example of this is seen in the brain stem, where 5-HIAA concentrations were significantly affected by confinement stress only in HR fish (c.f. Fig 1A). Thus, it could be concluded that 5HT systems are activated by confinement stress to a larger extent in HR than in LR fish. On the other hand, brain stem 5-HIAA/5-HT ratios were higher in LR fish both in the control condition and after stress (fig. 1C). The apparent contradiction is probably caused by HR fish, but not LR fish, responding to stress by an increase in 5-HT concentrations in this brain region (fig. 1B). The 5-HIAA/5-HT ratios however suggest that the proportion of 5-HT catabolized by monoamine oxidase (MAO), relative to total 5-HT content, was greater in LR fish, both in the control condition and during confinement stress. This result may be due to differences in functional 5-HT release, MAO enzyme activity, or in the efficiency of 5-HT uptake from the intracellular space.

Elevated 5-HIAA/5-HT ratios in LR fish due to increased 5-HT release in this group would at first hand appear contradictory as there is evidence that 5-HT acts as a stimulus on the HPI-axis in teleost fish, similar to in mammals [Winberg et al., 1997]. On the other hand, differential cortisol secretion in HR and LR fish might depend on differences in interrenal responsiveness [Pottinger and Carrick, 2001b], rather than central control of the HPI-axis. In fact, the observed differences in brain serotonergic activity between HR and LR fish might be attributed to differences in circulating cortisol as well as to alterations in intrinsic properties of the neural systems. Glucocorticoid hormones can affect the activity of serotonergic neurons both directly [Chaouloff, 1993, 2000], and 
through interactions with other signal substances. Glucocorticoids for instance have regionally dependent effects on brain corticotrophin-releasing hormone (CRH, or corticotrophin-releasing factor, CRF) gene expression in mammals [Schulkin et al., 1998], and CRH in turn has been shown to affect the firing rate of raphe 5-HT neurons [Lowry et al., 2000]. Furthermore, glucocorticoids are reported to have an inhibitory effect on brain MAO in mammals [Veals et al., 1977; Cvijic et al., 1995]. Effects of glucocorticoids on MAO have to our knowledge not been reported in fish, but an inhibitory effect would be consistent with decreased 5-HIAA/5-HT ratios in HR as compared to LR fish. It is also possible that selection for stress responsiveness led to genetically determined differences in MAO. Such differences have been associated with personality traits in human [reviewed by Shih and Thompson, 1999]. Finally, a direct influence of glucocorticoids on 5-HT reuptake cannot be excluded [Fernandes et al., 1997], but evidence for such an effect is inconclusive [see e.g. the review by Chaouloff, 2000]. An association between 5-HT transporter gene polymorphisms and mood alterations has also been reported in humans [Lesch et al., 1996].

Increased brain stem 5-HT in HR fish as compared to LR fish after confinement points towards differential effects of stress on 5-HT synthesis in the two populations. Glucocorticoids may again be responsible, either through effects on precursor availability, or through effects on synthetic enzymes (reviewed by Chaouloff [1993, 2000]). Evidence on the possible role of cortisol in the regulation of monoamine synthesis in teleost fish is lacking, but in general it would appear that fish and mammalian monoamine systems display extensive similarities in both function and anatomy [Parent et al., 1984; Hornby 
and Piekut, 1990; Jacobs and Azmitia, 1992; Winberg and Nilsson, 1993; Ma, 1994]. A similar influence of adrenal / interrenal steroids on monoamine functioning in these vertebrate groups therefore can not be excluded.

Similar to 5-HT, stressed HR fish displayed increased DA and DOPAC levels in the brain stem, as compared to both controls from the same population and stressed LR fish (c.f. fig. 1D, E). The simultaneous increase in the concentration of both the monoamine and its metabolite suggests that both synthesis and metabolism of the transmitter were increased after stress in high-responsive trout. Also supporting a theory of differential effects of stress on catecholamine synthesis in the two groups was the increase in NE concentrations seen in the telencephalon and optic tectum of HR, but not LR fish, after stress (cf. fig. 2H, 3H). Glucocorticoids may also act stimulatory on tyrosine hydroxylase [Dunn et al., 1978; Lucas et al., 1998], again making it possible that increased neurotransmitter concentrations in HR fish during stress is a consequence of increased synthesis due to elevated glucocorticoid levels. Glucocorticoids may also influence catecholaminergic systems through effects on neurotransmitter release, MAO, uptake sites, or pre- and postsynaptic receptor densities [Veals et al., 1977; Gilad et al., 1987; Piazza et al., 1996; Marinelli et al., 1998; Day et al., 1999; Lammers et al., 1999; RougéPont et al., 1999].

Genetically determined differences in dopaminergic activity have also been connected to differences in behavior and altered HPA-axis activity in rats [Cools et al., 1990, 1995, 1996a, b]. Using a selection model based on the extent of stereotypic gnawing elicited by 
the dopamine D1/D2 receptor agonist apomorphine Cools et al. [1990], found that high susceptibility to apomorphine-induced stereotypic behavior co-occured with increased locomotor activity in a novel environment. The apomorphine susceptible (apo-sus) rats also showed increased tyrosine hydroxylase mRNA and D2 receptor binding in the nigrostratial and tuberoinfundibular DA pathways [Rots et al., 1996a], and coherent with measures of increased tuberoinfundibular DA activity, it was also shown that the prolactin response to stress was significantly decreased in apo-sus rats, as compared to the apo-unsus strain originating from the same population [Rots et al., 1996b]. Stress-induced $\mathrm{ACTH}$ and total as well as free corticosterone levels remained significantly elevated longer in apo-sus animals as compared to the apounsus strain, suggesting a reduced ability to terminate stress-induced ACTH release, and therefore corticosteroid feedback resistance in the apo-sus strain [Rots et al., 1995, 1996b]. It would appear then the physiological and behavioral characteristics of the apo-sus strain of Wistar rats corresponds quite well to those of HR rainbow trout, indicating that both the teleost and the mammalian model represent selection for opposing physiological-behavioural stress coping strategies [Koolhaas et al., 1999].

A stimulatory role for brain dopaminergic systems in locomotor activity has long been acknowledged, and this point of view has recently been confirmed in studies with dopamine transporter knockout mice [Spielewoy et al., 2000], whereas 5-HT is thought to have an inhibitory effect on locomotor activity [Winberg et al., 1993]. In rats, glucocorticoids have been shown to facilitate dopamine-dependent behaviors, probably by glucocorticoid-receptor mediated effects on dopamine release [Marinelli et al., 1998]. 
It therefore seems likely that an interaction between cortisol and brain dopaminergic systems is involved in the elevation of behavioral activity observed in HR fish when subjected to a conspecific intruder [Øverli et al., 2001].

Other behavioral characteristics of HR rainbow trout are a slow recovery to feed after transfer to a new environment [Øverli et al., 2001] and a tendency to become socially subordinate in dyadic encounters [Pottinger and Carrick, 2001a]. Interestingly, a negative relationship between stressor novelty-induced locomotor activity and social competitive ability also have been demonstrated in cynomolgus monkeys (Macaca fascicularis) [Morgan et al., 2000]. Individually housed monkeys with high levels of locomotion in an open-field test after a low dose of cocaine (which has been shown to increase CNS dopamine) were more likely to become subordinate in subsequent group rearing [Morgan et al., 2000].

The current study shows that differential HPI-axis responsiveness in rainbow trout is associated with differences in brain monoaminergic activity, which in part correspond to changes seen in mammalian models of genetically determined differences in stress responsiveness and behavior. It is however not known to what extent these differences are caused by genetically determined alterations in the intrinsic properties of brain monoaminergic systems, or are a result of differential cortisol levels. Furthermore, it is not known at what site(s) within the HPI-axis selection for stress responsiveness operates in rainbow trout. Recent results however suggest that the differences in stress induced cortisol concentrations might arise from differences in interrenal function, rather than in 
central HPI-axis control [Pottinger and Carrick 2001b]. Thus, the possibility should be considered that differences in neurochemistry and behavior between these lines of fish are a result of variation in interrenal influence on brain functions, rather than the opposite.

\section{Acknowledgements}

This study has been carried out with financial support from the Commission of the European Communities, Agriculture and Fisheries (FAIR) specific RTD program CT95152 'Selective breeding for stress tolerance in aquacultured fish' and from the Natural Environment Research Council of the UK. Further financial support was received from The Swedish Council for Forestry and Agricultural Research (to ØØ and SW), the Axelsson-Johnson Foundation and the Längmanska Foundation (to ØØ).

\section{References}

Aldegunde, M., J.L. Soengas, and G. Rozas (2000) Acute effects of L-tryptophan on tryptophan hydroxylation rate in brain regions (hypothalamus and medulla) of rainbow trout (Oncorhynchus mykiss). J. Exp. Zool., 286: 131-135.

Bertolucci-D'Angio, M., A. Serrano, and B. Scatton (1990) Mesocorticolimbic dopaminergic systems and emotional states. J. Neurosci. Meth., 34: 135-142.

Blanchard, D.C., R.R. Sakai, B. McEwen, S.M. Weiss, and R.J. Blanchard (1993) Subordination stress: Behavioral, brain and neuroendocrine correlates. Behav. Brain. Res., 58: 113-121.

Boadle-Biber, M.C. (1993) Regulation of serotonin synthesis. Prog. Biophys. Mol. Biol., 
$60: 1-15$.

Brambilla, F., G. Perna, R. Bussi, and L.D. Bellodi (2000) Dopamine function in obsessive compulsive disorder: cortisol response to acute apomorphine stimulation. Psychoneuroendocrinology, 25: 301-310.

Chaouloff, F. (1993) Physiopharmacological interactions between stress hormones and central serotonergic systems. Brain. Res. Rev., 18: 1-32.

Chaouloff, F. (2000) Serotonin, stress and corticoids. J. Psychopharmacol., 14: 139-151.

Corio, M., M.C. Peute, and H.W.M. Steinbusch (1991). Distribution of serotonin- and dopamine-immunoreactivity in the brain of the teleost Clarias gariepinus. J. Chem. Neuroanat., 4: 79-95.

Cvijic, G., R. Radojicic, J. Djordjevic, and V. Davidovic (1995) The effect of glucocorticoids on the activity of monoamine oxidase, copper-zinc superoxide dismutase and catalase in the rat hypothalamus. Funct. Neurol., 10: 175-181.

Day, H.E.W., S. Campeau, S.J. Watson, and H. Akil (1999) Expression of $\alpha_{1 b}$ adrenoceptor mRNA in corticotropin-releasing hormone-containing cells of the rat hypothalamus and its regulation by corticosterone. J. Neurosci., 19: 10098-10106.

Dunn, A.J., N.B. Gildersleeve, and H.E. Gray (1978) Mouse brain tyrosine hydroxylase and glutamic acid decarboxylase following treatment with adrenocorticotrophic hormone, vasopressin or corticosterone. J. Neurochem., 31: 977-982.

Ekström, P. and T. van Veen (1984) Distribution of 5-HT in the brain of the teleost Gasterosteus aculeatus L. J. Comp. Neurol., 226: 307-320.

Ekström, P., and S.O.E. Ebbesson (1989) Distribution of serotonin-immunoreactive neurons in the brain of sockeye salmon fry. J. Chem. Neuroanat., 2: 201-213. 
Fernandes, C., C.R. McKittrick, S.E. File, and B.S. McEwen (1997) Decreased 5-HT $1 \mathrm{~A}$ and increased 5- $\mathrm{HT}_{2 \mathrm{~A}}$ receptor binding after chronic corticosterone associated with a behavioral indication of depression but not anxiety. Psychoneuroendocrinology, 22: 477-491.

Fevolden, S.E., K.H. Røed, K.T. Fjalestad, and J. Stien (1999) Poststress levels of lysozyme and cortisol in adult rainbow trout: heritabilities and genetic correlations. J. Fish Biol., 54: 900-910.

Gilad, G.M., J.M. Rabey, and V.H. Gilad (1987) Presynaptic effects of glucocorticoids on dopaminergic and cholinergic synaptosomes. Implications for rapid endocrineneural interactions in stress. Life Sci., 40: 2401-2408.

Hornby, P.J, and D.T. Piekut (1990) Distribution of catecholamine-synthesizing enzymes in goldfish brains: presumptive dopamine and norepinephrine neuronal organization. Brain, Behav. Evol., 35: 49-64.

Höglund, E., P.H.M. Balm, and S. Winberg (2000) Skin darkening, a potential social signal in subordinate Arctic charr (Salvelinus alpinus): The regulatory role of brain monoamines and pro-opiomelanocortin-derived peptides. J. Exp. Biol., 203: $1711-1721$.

Jacobs, B.L, and E.C. Azmitia (1992) Structure and function of the brain serotonin system. Physiol. Rev., 72: 165-229.

Kah, O., and P. Chambolle (1983) Serotonin in the brain of the goldfish, Carrassius auratus. Cell Tissue Res., 234: 319-333.

Lesch, K.P., D. Bengel, A. Heils, S.Z. Sabol, B.D. Greenberg, S. Petri, J. Benjamin, C.R. 
Muller, D.H. Hamer, and D.L. Murphy (1996) Association of anxiety-related traits with a polymorphism in the serotonin transporter gene regulatory region. Science, 274: $1527-1531$.

Lammers, C.H., U.M. D'Souza, Z.H. Qin, S.H. Lee, S. Yajima, and M.M. Mouradian (1999) Regulation of striatal dopamine receptors by corticosterone: an in vivo and in vitro study. Mol. Brain. Res., 69: 281-285.

Lepage, O., Ø. Øverli, E. Petersson, T. Järvi, and S. Winberg (2000) Differential stress coping in wild and domesticated sea trout. Brain Behav. Evol., xx.

Lowry, C.A., J.E. Rodda, S.L. Lightman, and C. D. Ingram (2000) Corticotropinreleasing factor increases in vitro firing rates of serotonergic neurons in the rat dorsal raphe nucleus: evidence for activation of a topographically organized mesolimbocortical serotonergic system. J. Neurosci., 20: 7728-7736.

Lucas, L.R., P. Pompei, J. Ono, and B.S. McEwen (1998) Effects of adrenal steroids on basal ganglia neuropeptide mRNA and tyrosine hydroxylase radioimmunoreactive levels in the adrenalectomized rat. J. Neurochem., 71: 833-843.

de Kloet, E.R., S.M. Korte, N.Y. Rots, and M.R. Kruk (1996) Stress hormones, genotype, and brain organization. Ann. N. Acad. Sci., 794: 179-191.

Koolhaas, J.M., S.M. Korte, S.F. De Boer, B.J. Van Der Vegt, C.G. Van Reenen, H. Hopster, I.C. De Jong, M.A.W. Ruis, and H.J. Blokhuis (1999) Coping styles in animals: current status in behavior and stress-physiology. Neurosci. Biobehav. Rev., 23: 925-935.

Ma, P.M. (1994) Catecholaminergic systems in the zebrafish. II. Projection pathways and pattern of termination of the locus coeruleus. J. Comp. Neurol., 344: 256-259. 
Marinelli, M., B. Aouizerate, M. Barrot, M. Le Moal, and P.V. Piazza (1998) Dopaminedependent responses to morphine depend on glucocorticoid receptors. Proc. Natl. Acad. Sci., 95: 7742-7747.

Morgan, D., K.A. Grant, O.A. Prioleau, S.H. Nader, J.R. Kaplan, and M.A. Nader (2000) Predictors of social status in cynomolgus monkeys (Macaca fascicularis) after group formation. Am. J. Primatol., 52: 115-131.

Nikulina, E.M., D.F. Avgustinovich, and N.K. Popova (1992) Selection for reduced aggressiveness towards man and dopaminergic activity in Norway rats. Aggress. Behav., 18: 65-72.

Parent, A., D. Poitras, and L. Dubé (1984) Comparative anatomy of central monoaminergic systems. In Handbook of Chemical Neuroanatomy (ed. by A. Björklund and T. Hökfelt), Elsevier, Amsterdam, pp. 409-439.

Piazza, P.V., F. Rougé-Pont, V. Deroche, S. Maccari, H. Simon, and M. Le Moal (1996) Glucocorticoids have state-dependent stimulant effects on the mesencephalic dopaminergic transmission. Proc. Natl. Acad. Sci., 93: 8716-8720.

Pickering, A. D., T.G. Pottinger, and J.P. Sumpter (1987) On the use of dexamethasone to block the pituitary-interrenal axis in the brown trout, Salmo trutta L.. Gen. Comp. Endocrinol., 65: 346-353.

Plotsky, P.M., E.T. Cunningham, and E.P. Widmaier (1989) Catecholaminergic modulation of corticotropin-releasing factor and adrenocorticotropin secretion. Endocr. Rev., 10: 437-458.

Popova, N.Y., A.V. Kuliakov, E.M. Nikulina, E.Y. Kozlachkova, and G.B. Maslova 
(1991a) Serotonin metabolism and serotonergic receptors in Norway rats selected for low aggressiveness to man. Aggress. Behav., 17: 207-214.

Popova, N.K, N.N. Voitenko, A.V. Kulikov, and D.F. Avgustinovich (1991b) Evidence for the involvement of central serotonin in mechanism of domestication of silver foxes. Pharmacol. Biochem. Behav., 40: 751-756.

Pottinger, T. G., and T.R Carrick (1999) Modification of the plasma cortisol response to stress in rainbow trout by selective breeding. Gen. Comp. Endocrinol., 116: $122-132$.

Pottinger, T. G., and T.R Carrick (2001a) Stress responsiveness affects dominantsubordinate relationships in rainbow trout?. Horm. Behav., in press.

Pottinger, T. G., and T.R Carrick (2001b) ACTH does not mediate divergent stress responsiveness in rainbow trout. Comp. Biochem. Physiol. 129A: 399-404.

Rots, N.Y., A.R. Cools, M.S. Oitzl, J. De Jong, W. Sutanto, and E.R De Kloet (1996) Divergent prolactin and pituitary-adrenal activity in rats selectively bred for different dopamine responsiveness. Endocrinology, 137: 1678-1686.

Rougé-Pont, F., D.N. Abrous, M. Le Moal, and P. V. Piazza (1999) Release of endogenous dopamine in cultured mesencephalic neurons: influence of dopaminergic agonists and glucocorticoid antagonists. Eur. J. Neurosci., 11: 2343-2350.

Sallinen J., A. Haapalinna, E. MacDonald, T. Viitamaa, J. Lahdesmaki, E. Rybnikova, M. Pelto-Huikko, B.K. Kobilka, M. Scheinin (1998) Genetic alteration of the $\alpha_{2}$ adrenoceptor subtype $\mathrm{c}$ in mice affects the development of behavioral despair and stress-induced increases in plasma corticosterone levels. Mol. Psych., 4: 443-452. 
Schulkin, J, P.W. Gold, and B.S. McEwen (1998) Induction of corticotropin-releasing hormone gene expression by glucocorticoids: implication for understanding the states of fear and anxiety and allostatic load. Psychoneuroendocrinology, 23: 219243.

SheaMoore, M.M., O.P. Thomas, J.A. Mench (1996) Decreases in aggression in tryptophan-supplemented broiler breeder males are not due to increases in blood niacin levels. Poultry Science, 75: 370-374.

Shih, J.C., and R.F. Thompson (1999) Monoamine oxidase in neuropsychiatry and behavior. Am. J. Hum. Genet., 65: 593-598.

Stanford, S.C. (1993) Monoamines in response and adaption to stress. In Stress From Synapse to Syndrome (ed. by S.C. Stanford and P. Salmon), Academic Press, London, pp. 282-331.

Spielewoy, C., C. Roubert, M. Hamon, M. Nosten-Bertrand, C. Betancur, and B. Giros (2000) Behavioral disturbances associated with hyperdopaminergia in dopaminetransporter knockout mice. Behav. Pharmacol., 11: 279-290.

Veals, J.W., C.A. Korduba, and S. Symchowicz (1977) Effect of dexamethasone on monoamine oxidase inhibiton by iproniazid in rat brain. Eur. J. Pharmacol., 41: 291-299.

Winberg, S., G.E. Nilsson, and K.H. Olsén (1992) The effect of stress and starvation on brain serotonin utilization in Arctic charr (Salvelinus alpinus). J. Exp. Biol., 165: 229-239.

Winberg, S., and G.E. Nilsson (1993) Roles of brain monoamine neurotransmitters in 
agonistic behavior and stress reactions, with particular reference to fish. Comp. Biochem. Physiol., 106C: 597-614.

Winberg, S., A. Nilsson, P. Hylland, V. Söderstrom, and G.E. Nilsson (1997) Serotonin as a regulator of hypothalamic-pituitary-interrenal activity in teleost fish. Neurosci. Lett., 230: 113-116.

Øverli, Ø., S. Winberg, B. Damsgård, and M. Jobling (1998) Food intake and spontaneous swimming activity in Arctic char, Salvelinus alpinus (L): role of brain serotonergic activity and social interactions. Can. J. Zool., 76:1366-1370.

Øverli, Ø., Harris, C. A., and Winberg, S. (1999) Short-term effects of fights for social dominance and the establishment of dominant-subordinate relationships on brain monoamines and cortisol in Rainbow trout. Brain Behav. Evol, 54: 263-275.

Øverli, Ø., T.G. Pottinger, T.R. Carrick, E. Øverli, and S. Winberg (2001) Differences in behavior between rainbow trout selected for high and low stress responsiveness. J. Exp. Biol., in press 
Table 1. Plasma cortisol (ng/ml) (mean $\pm \mathrm{SE})$ in low- and high-responsive (LR, HR) rainbow trout when reared in isolation (controls) and following $1 \mathrm{~h}$ confinement stress.

\section{Group}

LR Control

HR Control

LR Confinement

HR Confinement
[Cortisol] and post hoc significance levels

$$
\begin{aligned}
& 23.6 \pm 6.1 \\
& 40.5 \pm 11.4 \\
& 51.6 \pm 7.5^{*} \\
& 72.5 \pm 6.7\left[^{*}\right]^{* *}
\end{aligned}
$$

Post-hoc significance levels are indicated by asterisks, where * is used to indicate a difference between stressed fish and controls from the same population, and $\left[{ }^{*}\right]$ indicates a difference between LR and HR fish $\left({ }^{*} \mathrm{p}<0.05,{ }^{* *} \mathrm{p}<0.01\right)$ (ANOVA followed by the Tukey HSD post-hoc test). 


\section{Figure legends}

Fig 1. Tissue concentrations of monoamines and monoamine metabolites (ng/g), and corresponding metabolite/monoamine ratios (mean $\pm \mathrm{SE}$ ) in the brain stem of low responsive (LR) and high responsive (HR) rainbow trout when reared in isolation (controls) or following $1 \mathrm{~h}$ confinement stress. A-C are the results for serotonin and metabolite concentrations (A: 5-HIAA, B: 5-HT, and C: 5-HIAA/5-HT ratios), D-F are the results for dopamine and metabolite concentrations (D: DOPAC, E: DA, F: DOPAC/DA ratios), and G-I are the results for norepinephrine and metabolite concentrations (G: MHPG, H: NE, and I: MHPG/NE ratios). Post-hoc significance levels (ANOVA followed by the Tukey HSD post-hoc test) are indicated by asterisks, where * is used to indicate a difference between stressed fish and controls from the same population, and brackets [*] indicate a difference between LR and HR fish $\left({ }^{*} \mathrm{p}<0.05,{ }^{*} \mathrm{p}<0.01\right.$, $* * * \mathrm{p}<0.0001)$

Fig 2. Tissue concentrations of monoamines and monoamine metabolites (ng/g), and corresponding metabolite/monoamine ratios (mean $\pm \mathrm{SE}$ ) in the telencephalon of low responsive (LR) and high responsive (HR) rainbow trout when reared in isolation (controls) or following $1 \mathrm{~h}$ confinement stress. A-C are the results for serotonin and metabolite concentrations (A: 5-HIAA, B: 5-HT, and C: 5-HIAA/5-HT ratios), D-F are the results for dopamine and metabolite concentrations (D: DOPAC, E: DA, F: DOPAC/DA ratios), and $\mathrm{G}-\mathrm{I}$ are the results for norepinephrine and metabolite concentrations (G: MHPG, H: NE, and I: MHPG/NE ratios). Post-hoc significance levels 
(ANOVA followed by the Tukey HSD post-hoc test) are indicated by asterisks, where * is used to indicate a difference between stressed fish and controls from the same population, and brackets $\left[{ }^{*}\right]$ indicate a difference between LR and HR fish $\left({ }^{*} \mathrm{p}<0.05,{ }^{* *} \mathrm{p}<0.01\right.$, $* * * \mathrm{p}<0.0001)$

Fig. 3. Tissue concentrations of monoamines and monoamine metabolites (ng/g), and corresponding metabolite/monoamine ratios (mean $\pm \mathrm{SE}$ ) in the optic tectum of low responsive (LR) and high responsive (HR) rainbow trout when reared in isolation (controls) or following $1 \mathrm{~h}$ confinement stress. A-C are the results for serotonin and metabolite concentrations (A: 5-HIAA, B: 5-HT, and C: 5-HIAA/5-HT ratios), D-F are the results for dopamine and metabolite concentrations (D: DOPAC, E: DA, F: DOPAC/DA ratios), and G-I are the results for norepinephrine and metabolite concentrations (G: MHPG, H: NE, and I: MHPG/NE ratios). Post-hoc significance levels (ANOVA followed by the Tukey HSD post-hoc test) are indicated by asterisks, where * is used to indicate a difference between stressed fish and controls from the same population, and brackets $\left[{ }^{*}\right]$ indicate a difference between LR and HR fish $\left({ }^{*} \mathrm{p}<0.05,{ }^{* *} \mathrm{p}<0.01\right.$, $* * * \mathrm{p}<0.0001)$.

Fig. 4. Tissue concentrations of monoamines and monoamine metabolites (ng/g), and corresponding metabolite/monoamine ratios (mean $\pm \mathrm{SE}$ ) in the hypothalamus of low responsive (LR) and high responsive (HR) rainbow trout when reared in isolation (controls) or following $1 \mathrm{~h}$ confinement stress. A-C are the results for serotonin and metabolite concentrations (A: 5-HIAA, B: 5-HT, and C: 5-HIAA/5-HT ratios), D-F are 
the results for dopamine and metabolite concentrations (D: DOPAC, E: DA, F:

DOPAC/DA ratios), and G-I are the results for norepinephrine and metabolite concentrations (G: MHPG, H: NE, and I: MHPG/NE ratios). Post-hoc significance levels (ANOVA followed by the Tukey HSD post-hoc test) are indicated by asterisks, where * is used to indicate a difference between stressed fish and controls from the same population, and brackets $\left[{ }^{*}\right]$ indicate a difference between LR and HR fish $\left({ }^{*} \mathrm{p}<0.05,{ }^{* *} \mathrm{p}<0.01\right.$, $* * * \mathrm{p}<0.0001)$ 
Fig. 1.
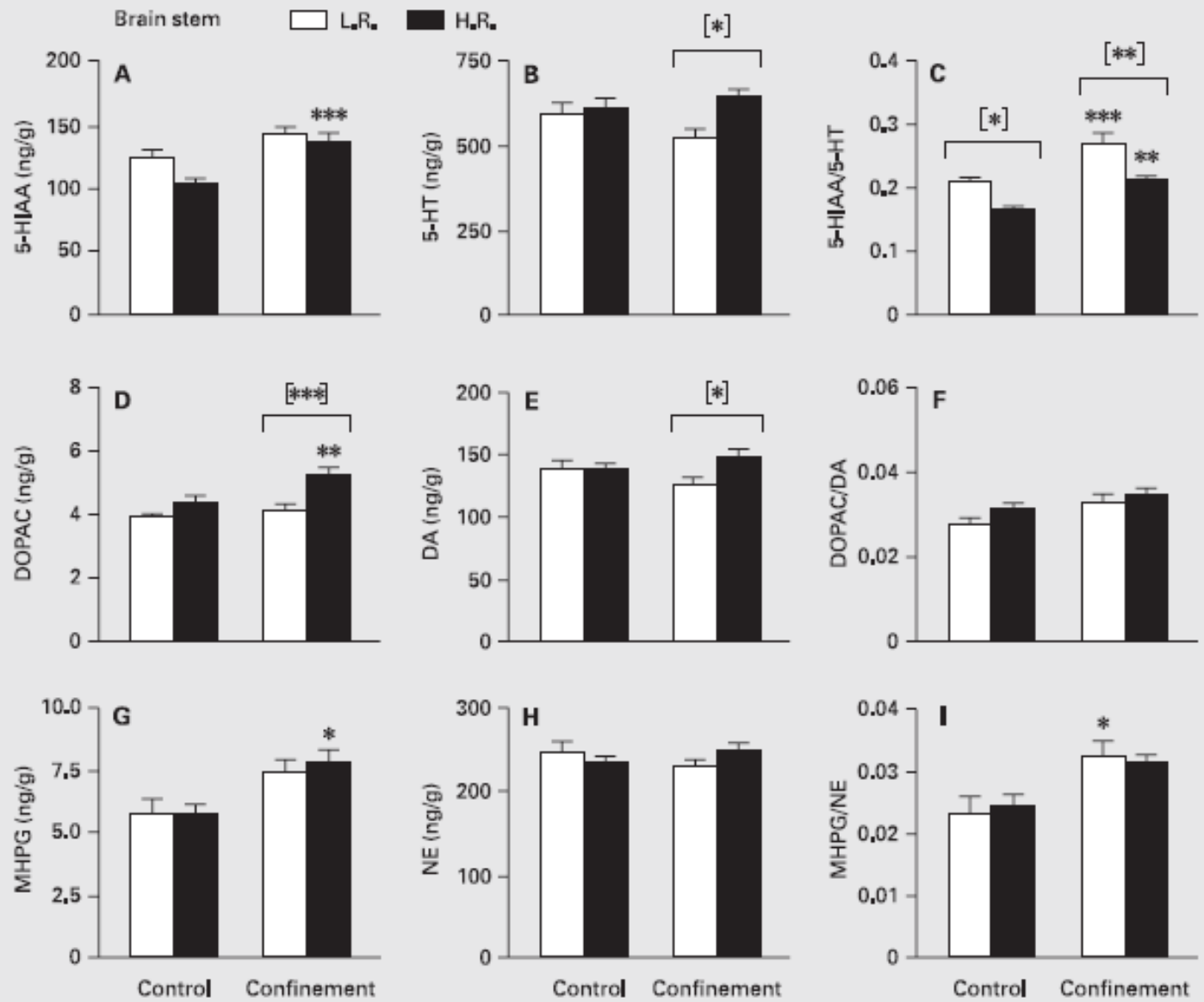
Fig. 2.
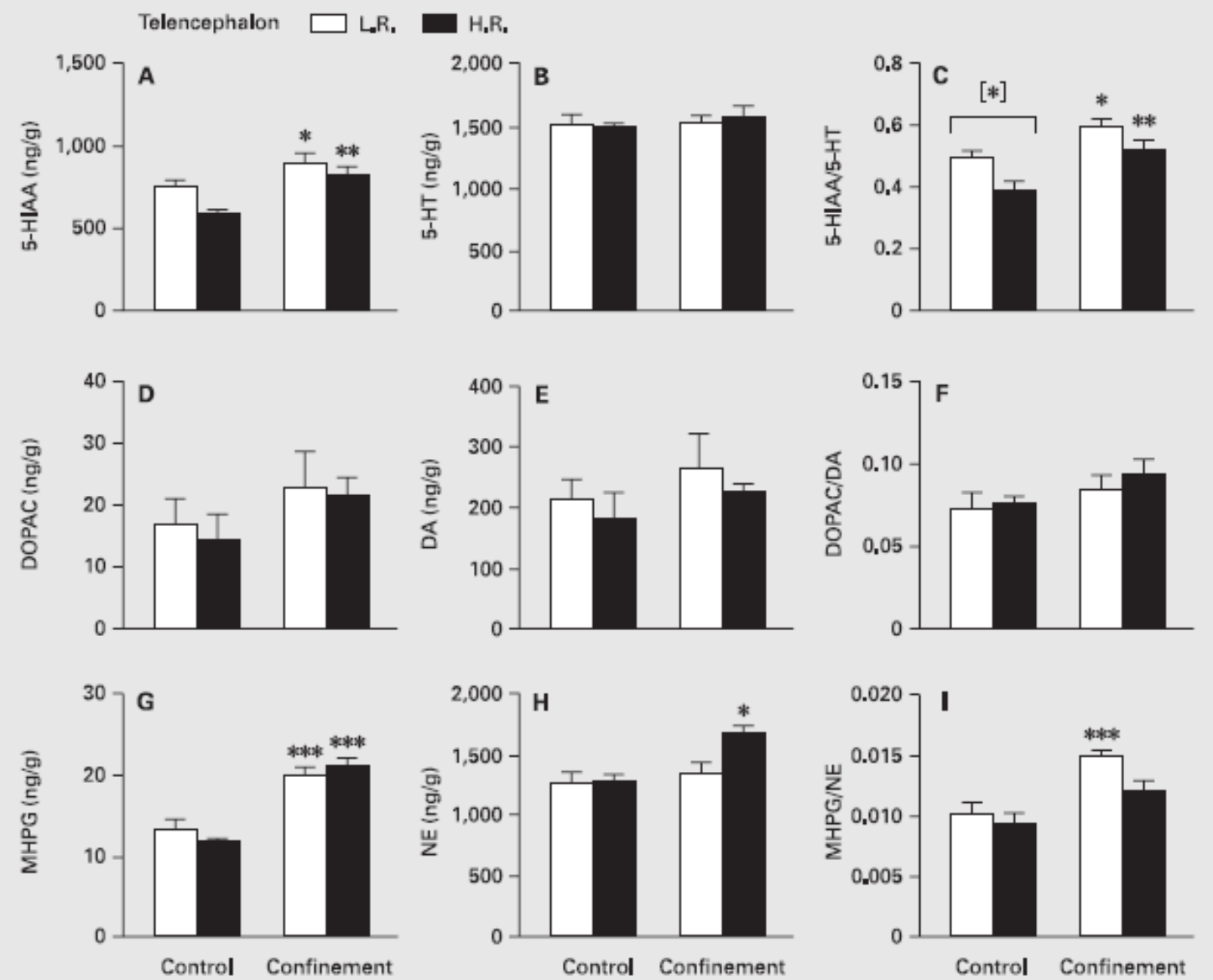
Fig. 3.
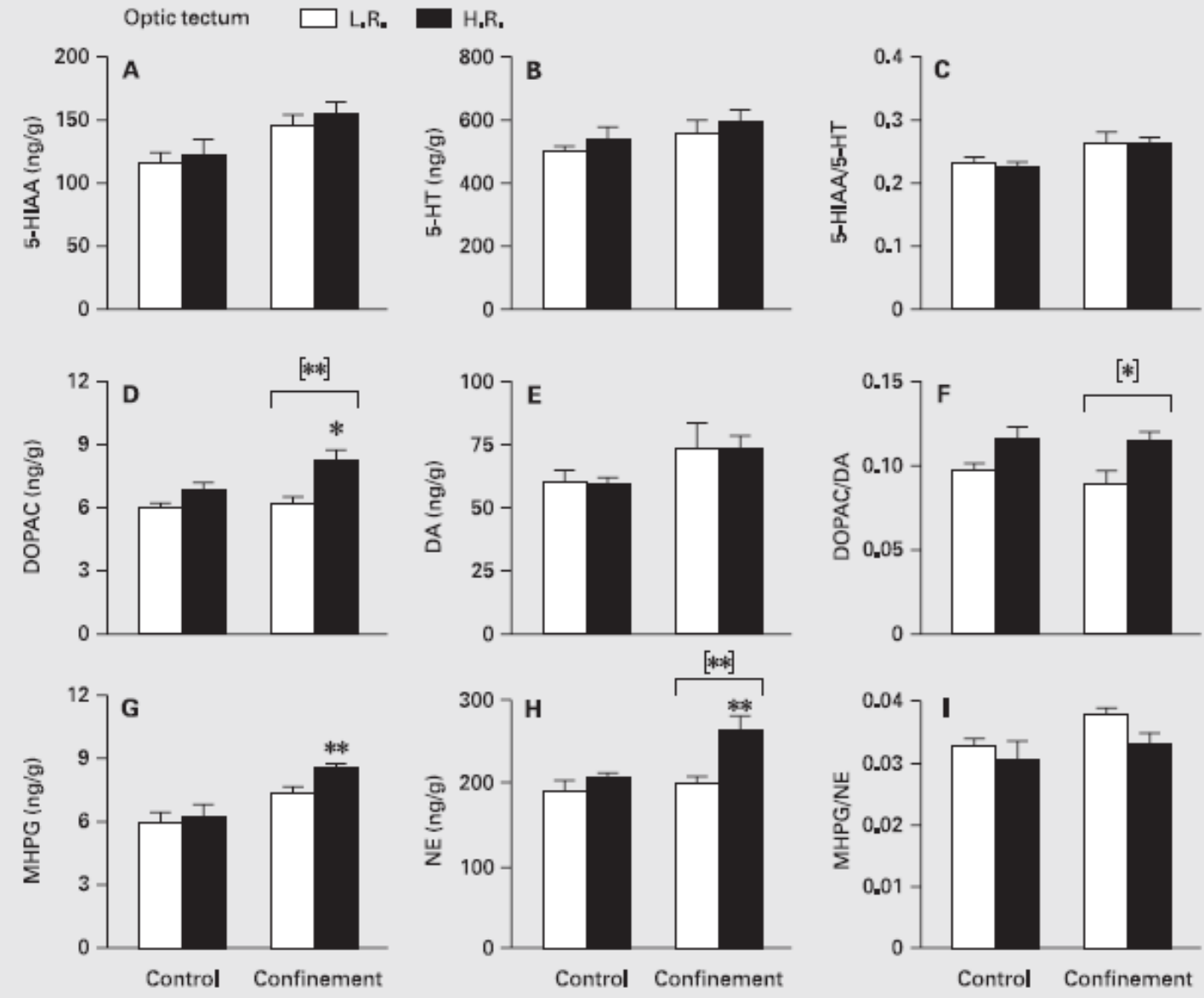
Fig. 4.
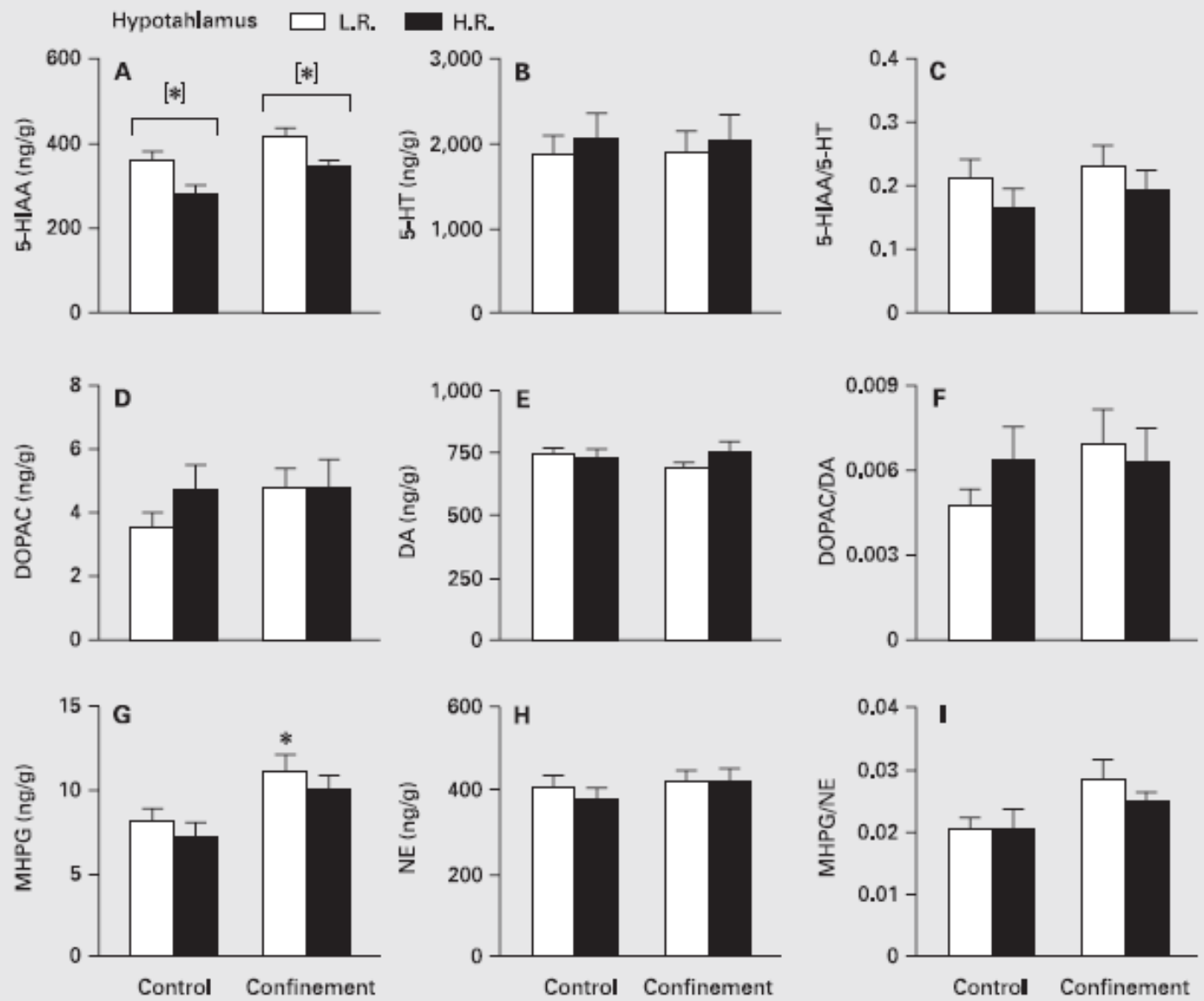